\title{
Accelerating the National Implementation of Electronic Health Records in Canada
}

\author{
Monique J. Francois, BBA \\ Ebere Ellison Obisike, DHSc
}

Burman University

doi: 10.19044/esj.2016.v12n15p65 URL:http://dx.doi.org/10.19044/esj.2016.v12n15p65

\begin{abstract}
Trends such as the aging population, long wait times, rising costs, and labour shortages in health professions are notable challenges facing the sustainability of Medicare in Canada. Healthcare reform, especially in primary care, will ensure efficiency and equitable access to healthcare in. Information and communication technologies (ICTs) such as electronic health records (EHRs) will play a pivotal role in reforming and sustaining Medicare. EHRs make healthcare safer, cost efficient and more integrated, and are necessary for the wider application of ICTs in the health sector. EHRs enhance decision-making capabilities for both providers and patients, especially in managing chronic diseases. Notwithstanding the numerous advantages of EHRs, Canada is slow to adopt a nation-wide EHR system. This paper analyzed existing data to establish the factors that may help to accelerate the national implementation of electronic health records in Canada. It defined EHRs, discussed their advantages and disadvantages, and barriers to its full application. Also, it explored key strategies for accelerating EHR initiatives in Canada, and suggested action plans and time frames for doing so.
\end{abstract}

Keywords: EHRs implementation, Canada's health info-structure, Information management and technology Accelerating the National Implementation of Electronic Health Records in Canada

\section{Introduction}

EHRs stand for electronic health records. They are secure, digital records of a person's medical history (Lau, Price and Bassi, 2014; Office of the Auditor General of Canada, 2010). They are managed by healthcare facilities (Duckett, 2012) for users' information needs (Ibid), and give access to authorized care providers or individuals (Ibid; Morris, 2005). EHRs can be fully computerized or contain only certain medical results (e.g. lab tests) 
used with paper-based patient charts (Urowitz et al. 2008; PwC, 2013). They contain four key elements: (1) a client registry of all enrolled patients and their personal information; (2) a provider registry of all health providers that are authorized to use the system; (3) a diagnostic imaging system that digitally collects, stores, displays and manages patient images and reports such as MRIs, X-rays, ultrasounds and CT scans; and (4) a drug information system in which healthcare providers can access, share and protect clients' drug history (Office of the Auditor General of Canada, 2010).

Similarly, electronic medical records (EMRs) contain patient demographics, medical and drug history, and diagnostic information and imaging results that can be integrated with billing and scheduling software (PwC, 2013; Zelmer \& Hagens, 2014). Correspondingly, a personal health record (PHR) is an individual's health record which uses data drawn from the EHR (Duckett, 2012). PHRs can be "truly transformative" as they reduce the duplication of tests, enable patient self-management, and shift power from providers to consumers (Duckett, 2012).

Unfortunately, Canada lags behind other Western countries in the adoption of EHRs (Gagnon et al. 2009; Rozenblum et al. 2011). For example, in 2008, Canada Health Infoway-a not-for-profit tasked to speed EHR implementation - hoped that by 2010, 50\% of Canadian health providers would adopt this system (Urowitz et al. 2008). But they did not meet their target by that date (Ibid). PHRs are slower to adopt because some physicians are reluctant to embrace information and communication technologies (ICTs) (Ibid). In addition, while many healthcare consumers want to access their medical history, most healthcare providers are unwilling to "give up ownership" of these records (Ibid, p. 5). Resistance from the medical community impedes EHR deployment as well as discussions about the implementation strategy, and criticisms of the necessity and scale of large investments (Deutsch, Duftschmid and Dorda, 2010).

Electronic health records (EHRs), electronic medical records (EMRs) and personal health records (PHRs) differ in their level of completeness and ownership (McGuinn, 2012). For instance, EHRs are comprehensive health records owned by health providers and are person-centric (Ibid). On the other hand, EMRs are partial provider-centric records that are owned by health organizations while PHRs are partial or complete records that are person-centric and owned by individuals (Ibid). Therefore, electronic medical records are a form of EHR technology (Scott 2015) whereas EHRs feed into personal health records (Duckett 2012).

This paper analyzed existing data to establish the factors that may help to accelerate the national implementation of electronic health records in Canada. A variety of data were obtained through peer-reviewed journal articles and highly recommended textbooks. All the journal articles used in 
this paper were published between 2005 and 2015 to ensure currency and to provide extensive historical information on the implantation of electronic health records in Canada.

Databases such as Canada Infoway, Canadian Medical Association, National Physician Survey Canada, Office of the Auditor General of Canada, and Health Canada were used as the primary search engines. Key words such as EHRs implementation, Canada's health infostructure, Information management and technology generating several research data. These data were assessed for currency, validity and suitability. Only articles and sections of the textbooks that were relevant to this topic were selected. The following sections underscore the outcomes of our data collection.

\section{The Pros and Cons of EHRs}

EHRs are essential to primary care reform. For instance, EHRs "link clinics, hospitals, pharmacies and other points of care (McGuinn et al., 2012)," and improve patient safety and access to services and the overall efficiency of the health care system (Grewal, 2014; McGuinn et al., 2012). When properly managed EHRs can reduce the duplication of tests and medical investigations (Duckett, 2012), the number of adverse drug events (Grewal, 2014; PwC, 2013), and encourage interdisciplinary teamwork and a continuity of care (Duckett, 2012; PwC, 2013).

Despite these benefits, EHR projects are complex and require large investments of time and resources (Ghazisaeidi et al. 2014). For example, Lau, Price and Bassi, (2014) suggest that EHRs use data from multiple sources and thus require a higher level of coordination and strategic planning. Also, EHRs contain sensitive and confidential information that may dispose patients to hackers and identity theft when adequate safeguards are not enforced (Atherley, 2009; Cavoukian \& Alvarez 2012). In additions to the above issues is the fact that centralized government management systems like those used for prescriptions and medications could allow criminals to impersonate physicians, patients and the management system itself (Atherley, 2009). If fraudsters could "outwit" the credit card industry, governments alike are not immune (Ibid). Furthermore, Atherley (2009) claims that Canada's privacy laws in electronic health are not robust enough to meet these challenges.

It is important to note that EHRs have different impacts on different stakeholders (PwC, 2013). For example, primary care and community-care providers may experience improved productivity and work flow, whereas patients may report higher satisfaction from more efficient clinical teams (Ibid). Similarly, the general public may experience benefits in terms of cost savings and improved preventive medicine (Ibid). These benefits and disadvantages are summarized below. 
Table 1: The Pros and Cons of Electronic Health Records (EHRs)

\begin{tabular}{|c|c|}
\hline Advantages & Disadvantages \\
\hline $\begin{array}{l}\text { Electronically integrates healthcare providers } \\
\text { by providing access to patients’ records } \\
\text { wherever and whenever it is needed. }\end{array}$ & $\begin{array}{l}\text { Requires significant investments in time, effort and } \\
\text { resources to learn and implement new technologies. }\end{array}$ \\
\hline $\begin{array}{l}\text { Encourages patient self-management (esp. for } \\
\text { chronic diseases) and data sharing among a } \\
\text { group of users. }\end{array}$ & Requires patient computer literacy. \\
\hline $\begin{array}{l}\text { Can help improve patients' health status, } \\
\text { satisfaction and health outcomes. }\end{array}$ & $\begin{array}{l}\text { Costly expenditures may discourage or slow the } \\
\text { adoption of EHRs. }\end{array}$ \\
\hline $\begin{array}{c}\text { Reduces health costs by more efficiently using } \\
\text { resources. }\end{array}$ & $\begin{array}{l}\text { Raises concerns on ownership and } \\
\text { privacy/confidentiality. }\end{array}$ \\
\hline $\begin{array}{l}\text { Enhances communication between care } \\
\text { providers and patients. }\end{array}$ & EHR deployment can take several years. \\
\hline $\begin{array}{l}\text { Empowers patients to better understand their } \\
\text { medical conditions and to take a more active } \\
\text { role in their personal care. }\end{array}$ & $\begin{array}{l}\text { EHRs are complex projects that require high } \\
\text { coordination among healthcare providers, } \\
\text { governments, sectors and organizations. }\end{array}$ \\
\hline Promotes patient-centred care. & $\begin{array}{l}\text { It is possible that the harms from EHR } \\
\text { implementation may neutralize the benefits. }\end{array}$ \\
\hline
\end{tabular}

Source: (Deutsch, Duftschmid \& Dorda 2010; Duckett, 2012; McGuinn et al., 2012;

Urowitz et. al, 2008)

\section{The Current State of EHRs in Canada}

Since the 1990s, Canada has improved its use of electronic health technologies. For example, in 1994, the federal government established the Health Advisory Council (IHAC) to enhance the use of emerging IT for economic, social and cultural advantages (Morris, 2005). The IHAC claimed that Canadians needed fast, easy access to information in order to thrive in the digital age (Ibid). Subsequent years saw the establishment of many organizations such as the Office of Health and the Information Highway $(\mathrm{OHIH})$ by Health Canada in 1997; the Federal/Provincial/Territorial Committee in 2000; and the Canada Health Infoway and Advisory of the Committee of Information and Emerging Technology (ACIET) in 2002 (Ibid). By 2003, the government tasked Canada Infoway with an additional \$600 million to implement a Canada-wide EHR system in support of the First Ministers' Accord on Healthcare Renewal (Ibid).

From 2006 to 2009, physicians' use of EMRs rose from 23\% to 36\% (Rozenblum et al., 2011). This figure paled in comparison to the $90 \%$ usage rates achieved in Australia, the UK, New Zealand and the Netherlands (Ibid). Similarly, in 2009, the federal government introduced Canada's Economic Action Plan to address the global recession (Government of Canada n.d.-a). According to Zelmer \& Hagens (2014), Canada Action Plan funded the efforts of Canada Health Infoway, the provinces, territories and health providers to implement projects that would accelerate the adoption of EMRs in primary care. This was due to the fact that strong policy and stakeholder consensus showed that the adoption of EMRs would improve work 
efficiency and reduce adverse drug events in community-based settings (Ibid). However, only 30\% of Canadian physicians used EHRs compared to $50 \%$ in the US and more than 90\% in Denmark and other European countries (Webster 2010a).

Two years later, the Commonwealth Fund Survey reported that 56\% of primary care physicians use EMRs in their practice and by March 31, 2013, "core elements" of the EHR program were in place for $55.4 \%$ of Canadians (Government of Canada n.d.-b). As of 2014, 64\% of primary care doctors used EMRs in their medical practice (Zelmer and Hagens, 2014). Although the trend shows progress, Canada's adoption rates still lag behind its Western counterparts (Grewal, 2014). There are a number of barriers to EHR deployment; from factors within the health system (such as a top-down system, a lack of leadership and resistance from clinicians) to those without (such as privacy and security threats posed by hackers and identity theft). EHR projects have a number of stakeholders (Ghazisaeidi et al. 2014; Rozenblum et al. 2011), so decision-makers must assess these barriers for each end-user (Deutsch, Duftschmid and Dorda, 2010).

\section{Challenges/Barriers to EHR Implementation in Canada}

\section{Financial Costs}

Finances are the greatest obstacle to EHR adoption (Urowitz et al. 2008; Kiah et al. 2014). Initially high start-up and ongoing costs, unexpected fees, or uncertainty about return on investment can slow progress (Paré et al. 2014; Kiah et al. 2014; Nguyen, Bellucci and Nguyen, 2014). EHR projects require large investments that may attract questions about the necessity of funding (Deutsch, Duftschmid and Dorda 2010) or the lack of solid evidence about the economic impact of healthcare IT (Kaye et al. 2010). Initiatives may not clearly articulate the costs versus the benefits for each stakeholder (i.e. payers, physicians, patients), which may lead to debates about who should pay (Ibid). EHR adoption requires unpaid work that provides very little financial incentives for physicians (Webster 2010a; Kaye et al. 2010). The federal government funds the provinces and territories through the Canada Health Infoway (Zelmer and Hagens 2014; Scott, 2015), but this occurs on a "first come, first served" basis (Scott, 2015). Unequal regional funding may force provinces and territories to differ in their stages of implementation which presents coordination problems when integrating regional EHRs with the national system (Ibid).

\section{Time, Effort and Workload}

EHRs require an investment of time, resources and coordinated effort (Ghazisaeidi et al. 2014). For instance, they require significant customization and time to select, purchase and implement the system (Paré et al. 2014; 
Gomillon and George, 2011). Also, participants must learn how to use the system, enter data, and convert paper-based records to electronic ones (Ibid). Similarly, unsuccessful projects have inadequate training programs or unrealistic time constraints (Nguyen, Bellucci and Nguyen, 2014). Furthermore, physicians' workloads are traditionally heavy; as an average physician works over 54 hours a week and spend an additional 110 hours a month on extra services such as on-call patient care, administration, teaching, and research (National Physician Survey, 2013). Accordingly, physicians with busy schedules may view EHRs as extra work or a waste of their already limited time (Grewal 2014; Kaye et al. 2010; Webster 2010b).

\section{Socio-cultural Barriers}

Physicians' mental attitude towards information technology, organizational readiness and culture are also impediments. Given that EHRs tend to reduce patient visits as more care is provided by phone or online (Webster, 2010b), physicians who are the actual custodians of EHRs may resent relinquishing this ownership to provide patients access (Urowitz et al., 2008). Since physicians are autonomous, they are concerned about the perceived effect that EHRs will have on their discretion and the number of patient visits (Bishop et al., 2015). Physicians’ age, specialty and comfort level with technology also play a role. Some physicians are too comfortable with the status quo and simply do not want to change (Grewal, 2014). Fortytwo percent of family physicians are more likely to use electronic only systems compared to only seventeen percent of specialists (National Physician Survey, 2014). Similarly, younger doctors (age 35 or younger) use fully computerized systems, whereas $36 \%$ of doctors age 65 or older are completely paper-based and only a third plan to adopt EHRs in the next two years (Ibid). According to Scott (2015), different learning curves, a resistance to change or a lack of computer literacy among other health professionals will also hinder adoption. Similarly, Gomillon and George (2011) state that end-users may be ill-prepared and thus unwilling to use the system or the organization's culture may not be conducive to the adoption of new technologies (Paré et al., 2014). This supports the belief that programs that lack strong leaders that know how to use the system well will also discourage usage (Scott, 2015).

\section{Technological Barriers}

EHRs face several technical problems such as inadequate infrastructure, slow system speed or unexpected outages, and limited or unreliable rural access to high-speed Internet (Scott, 2015; Green et al., 2015). While some physicians may want to adopt new systems, they may not have the required skills (Grewal, 2014). Also, some medical practices or 
clinics may have problems synchronizing the EHR system with clinicians' workflow (Kaye et al., 2010). In addition to the above issues is the possibility that access to different EHR vendors in different jurisdictions can also be a problem (National Physician Survey, 2014). For example, only $51 \%$ of doctors rated access as excellent or satisfactory, $23 \%$ rated it unsatisfactory and a quarter said that EHRs were unavailable in their region (Ibid). Medical practices may lack on-site personnel trained in IT and project management or due to location, lack external support in these areas (Deutsch, Duftschmid and Dorda 2010; Green et al., 2015).

\section{The Fee-for-Service Payment Model}

Fee-for-service, which is the primary method of payment for Canadian physicians, discourages interdisciplinary teamwork in both primary care (Duckett, 2012) and the adoption of EHRs (Webster, 2010a). Since EHRs may appear as an "expensive, puzzling new technology [that requires] large amounts of unpaid time... (Webster 2010a, p.752)," most physicians may not have or take the time to select an EHR system (Ibid). Also, there are concerns that it may threaten the traditional physician-patient consultation and reduce billing amounts (Ibid). Thus, fee-for-service doctors are less likely than salaried physicians to adopt EHR systems (Webster, 2010b).

\section{National Standards and Provincial/Territorial Harmonization}

Canada lacks a clear national strategy and harmonized provincial/territorial policies to guide EHR investments (Rozenblum et al., 2011). Data standards are inconsistent in the industry and account for regional differences in data formats and system designs (Paré et al., 2014). Poorly designed systems are less useful, especially when they cannot be integrated with existing ones (Nguyen, Bellucci and Nguyen, 2014). Thus, EHRs must not only be interoperable, but also easy to use (Ibid). Similarly, misaligning goals between the national strategy and the needs of clinicians, health organizations and businesses, and overemphasizing the national policy at the expense of regional integration would also hinder progress (Rozenblum et al., 2011).

\section{Lack of an Effective Policy Setting Authority}

Canada Infoway has very little governance (Webster, 2011) and is a "funding agency, not a policy setting body (Rozenblum et al. 2011, p.3)." Stronger leadership is needed to align the national e-health policy with the health system's needs (Ibid). A national "watchdog” would provide greater transparency and accountability for funding and spending (Webster, 2011). Independent analysts could assess, track and monitor e-health developments and provide impartial data to justify government expenditures (Ibid). 
Stakeholders are dissatisfied with the current political support and they question Canada Infoway's ability to meet its targets (Scott, 2015).

\section{Privacy and Security Concerns}

Without proper safeguards, EHRs may compromise patients’ privacy (Nguyen, Bellucci and Nguyen 2014; Cavoukian and Alvarez 2012; Exeter, Rodgers and Sabel, 2014). Current legislation includes the Personal Information Protection and Electronic Documents Act, 2000 (PIPED), which governs how private organizations disclose, collect, or use individuals' personal information (Scott, 2015); the Personal Health Information Protection Act, 2004 (PHIPA) in Ontario which clearly defines rules for collecting and disclosing personal data for secondary purposes (such as health research) (Cavoukian and Alvarez, 2012); and the Pan-Canadian Health Information Privacy and Confidentiality framework, 2005, which further governs public and private firms' use of personal health information (Scott, 2015). However, some critics find these safeguards inadequate to protect against identity theft (Atherley, 2009). Like credit card companies, governments are not immune to cyber-attacks and must develop more robust systems to protect Canadians' information (Ibid). Privacy systems must address issues such as de-identifying information used in health research, unauthorized access, data governance, and the need for transparency (Cavoukian and Alvarez, 2012). Until then, skeptics warn against adopting a Canada-wide EHR system (Atherley, 2009).

\section{Strategies to Accelerate EHR Implementation}

Optimizing EHR Deployment

EHR adoption has three stages in which key activities occur before, during and after implementation (Ghazisaeidi et al. 2014). When decisionmakers identify the need for an EHR system, they must conduct assessments (particularly a readiness assessment), develop strategic plans for implementation, select a vendor, and conduct a final system evaluation while providing maintenance and support services (Ibid). A Delphi study by Deutsch, Duftschmid and Dorda (2010) that compares the national EHR programs of five nations (Canada, Denmark, Australia, England and Germany) suggests that the following five areas are crucial to successful deployment: (1) acceptance and change management, (2) demonstration of benefits and funding, (3) project management, (4) health-policy-related goals and implementation strategy, and (5) basic legal requirements (particularly data protection). EHR programs are multi-faceted and affect a variety of stakeholders, so decision-makers must assess each barrier specific to each end-user (Ibid). 


\section{Stage 1: Pre-Implementation}

This phase entails data collection, systems design and planning activities that support EHR adoption (Paré et al., 2014). It identifies and prioritizes potential problems and aligns organizational needs with system features (Ibid). Strategic planning is the first and most crucial step before any funds are spent. A comprehensive roadmap is necessary (Ghazisaeidi et al., 2014), which means that Canada needs a clear national EHR policy that integrates provincial and territorial EHRs with the national system. Such a roadmap requires policy makers to establish clear national standards for EHRs and health IT with a well-established payment system. In doing so, clear information standards can improve usage rates and interoperability (Deutsch, Duftschmid and Dorda, 2010). This being said, the policies should be flexible and responsive to users' experiences (Scott, 2015). At the system level, EHRs must be well-designed, easy to use, reliable and secure (Lau, Price and Bassi, 2014). At the clinical level, end-users must clearly understand the benefits of EHRs and how these systems serve their needs (Ibid). Shared goals foster cooperation and less resistance to the system. A national policy-making authority should have a clear vision, realistic goals, and the corresponding strategies and time frames to achieve them. To this effect, a national policy requires strong leadership at both the political and organizational levels (Kaye et al., 2010; Rozenblum et al., 2011). Likewise, Strategic planners should estimate and justify costs while project management can coordinate partnerships between governments and key stakeholders.

In addition to strategic planning, pre-implementation requires a needs and readiness assessment; the financial, organizational and technical readiness of participants to adopt the system. Finances are a major hindrance (Scott, 2015; Urowitz et al., 2008), so governments and supporting organizations should offset physicians' start-up costs. Financial incentives such as physician reimbursements can foster clinician adoption (Lau, Price and Bassi, 2014). Support systems can help doctors choose an EHR vendor and provide technical assistance, training and skills development (Kaye et al., 2010). Organizational readiness entails assessing the current situation. Surveys and questionnaires measure current EHR usage and determine the needs of various organizations before adopting the system. Data standards will make information more comparable as researchers collect data from all provinces and territories to determine each region's stage of implementation. Once health professionals decide to try the system, they should select EHR vendors based on the fit between their organizational needs and the system's capabilities (Ghazisaeidi et al., 2014). 


\section{Stage 2: Implementation}

Social and human factors are crucial at this stage (Paré et al., 2014). Humans are inevitably the system users who vary in their technical competence, motivation and capabilities (Lau, Price and Bassi 2014). Managers' commitment and support, realistic workloads, and interoperable infrastructure all influence adoption (Ibid). Successful deployment hinges on training and technical support as organizations use the system. Participants must overcome their reluctance and gain the necessary competencies to use it efficiently. Vendors tend to provide limited support before and after implementation so firms, particularly low-resource practices, need ongoing support (Green et al., 2015). Primary care associations and other health systems that currently provide financial and operational support could receive additional funding to help these practices (Ibid). For example, OntarioMD uses a funding program to encourage physicians to adopt EMRs (Shaw, 2014). Clinics receive funds that offset software and deployment costs only if they adopt the system by a specific date (Ibid).

As firms adopt EHRs there is a need to address the fee-for-service payment model. The current model hinders teamwork; an inherent benefit of EHR systems (Armstrong and Armstrong 2008; Duckett 2012). Instead, blended payments are preferred (Ibid) and should link pay to patient outcomes (Rozenblum et al., 2011). Likewise, strategists must address physicians' attitudes by clearly defining EHR ownership and informing clinicians that patients have a legal right to their health information (Urowitz et al., 2008).

\section{Stage 3: Post-implementation}

In the final step, users need maintenance and ongoing support. Policy makers must address privacy concerns by developing a robust system to protect the information. For example, the Privacy by Design (PhD) model "proactively" incorporates privacy into IT design so that privacy and other functionalities can co-exist (Cavoukian and Alvarez, 2012). Security measures such de-identifying patients when data is used for secondary research; disclosure agreements with clear obligations and conditions; and revising and expanding the powers of provincial/territorial bodies that oversee privacy issues can help protect patients' health information (Ibid). Likewise, EHR infrastructure should use encryption services to authorize or deny access, and audit and report who uses the information and for what purposes (Ibid).

Decision-makers need meaningful ways to engage clinicians. One approach is the creation of a provincial clinical information office (Rozenblum et al., 2011). This office would work with clinicians to set investment priorities for health IT, establish EHR criteria, and create 
business plans for computerizing primary care and community-based practices (Ibid). Last but not least is system evaluation. The national EHR strategy should have ongoing assessments that ensure transparency and publicize the results (Lau, Price and Bassi, 2014). Public reporting allows for systems improvement and organizational learning that makes each implementation process more successful (Ibid). Meaningful evaluation requires the use of quality measures that can link standards to funding (Deutsch, Duftschmid and Dorda, 2010).

Figure one further explains how these strategies can be implemented.

Figure 1 Strategies to Accelerate EHR Implementation
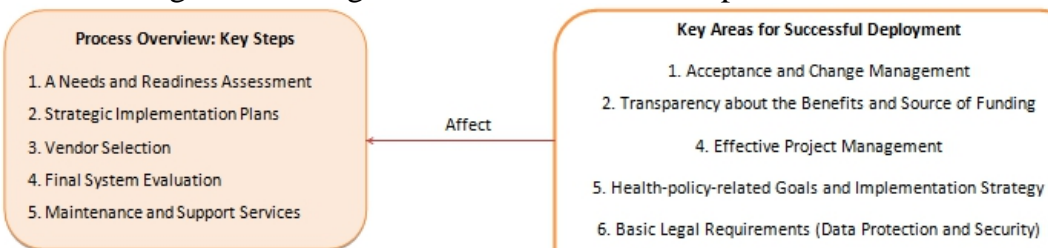

5. Health-policy-related Goals and Implementation Strategy 6. Basic Legal Requirements (Data Protection and Security)

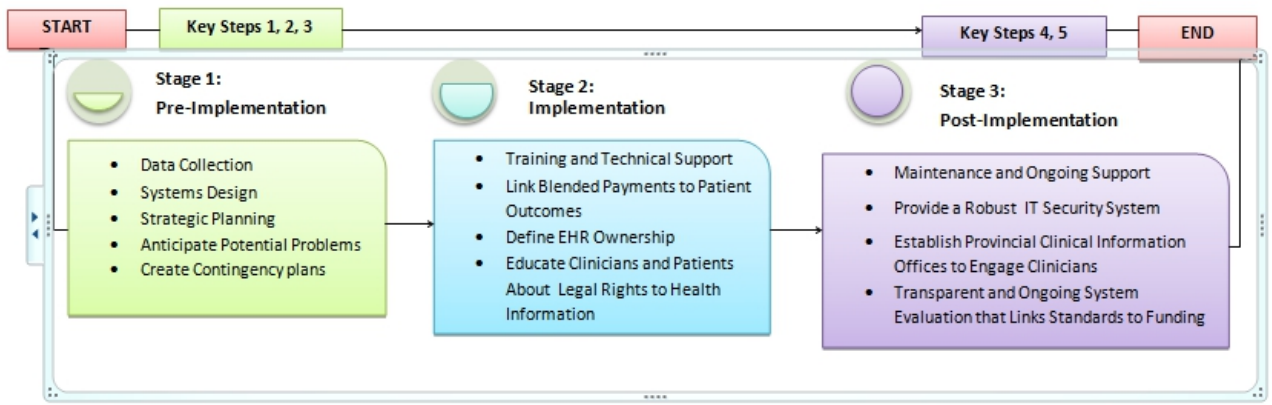

\section{Future Trends}

The 2003 and 2004 health accords provided a decade of steady funding to support health care reforms. The Health Council of Canada (HCC) was established to monitor and publish annual reports on the progress of these initiatives, and received funding from the federal government over the 10-year period (KPMG 2013). However, by April 2013, the federal government announced plans to stop funding as the Accord expired in 2014 (Ibid). As of March 31, 2014, both the Accord and the HCC ceased to exist (Health Council of Canada 2014). The Canada Health Transfer (CHT) and Canada Social Transfer (CST) were also affected by this action. In 2011, the Tory government announced that the CHT would continue at $6 \%$ per annum until 2016-2017, after which it will be reduced to 3\% per annum (Government of Canada, 2014). The CST will continue at 3\% per annum for 2014-2015 and onwards, and both transfers will be renegotiated in 2024 (Ibid). The 2014 Health Accord was not renewed and these developments show the federal government's weakening financial role and leadership in healthcare reform. 
Policy makers must make EHRs a top priority. Over the next ten years, Canada Infoway and supporting organizations should work to increase physician usage rates from two thirds to over ninety percent. Investing more money is not warranted considering our strained financial budgets. Instead, an efficient, sustainable health care system is the result of stronger leadership - political leadership that provides clear legislation for health initiatives, and organizational leadership from health care providers. Political action and careful coordination will ensure that each stakeholder in the healthcare system contributes. Accelerating EHR deployment in Canada is not a local issue-it is a national one that necessarily calls for federal leadership. The federal, provincial and territorial governments must collaborate to enact policies that are consistent with their shared goals (Health Council of Canada, 2014). They should build partnerships across sectors and patient groups, and extend the connectivity of EHRs to enable information sharing and patient access (Ibid). Lastly, national standards and quality improvement measures will make system-wide assessments easier. Better healthcare in Canada involves each stakeholder doing their part to improve the entire health system.

\section{Conclusion}

There is sufficient evidence to suggest that EHRs are valuable tools for healthcare reforms. Notwithstanding the barriers facing the broader use of EHRs in our health care facilities, health and social policy makers and stakeholders alike can work together to accelerate EHR deployment in Canada. EHRs are part of the broader health IT system that is improving the quality of care. The success of this system depends upon on the coordinated efforts between healthcare providers and key decision makers in governments and public/private organizations. While clinicians must provide access and become more comfortable using electronic records, both national and provincial policy makers must develop clearly defined goals for the adoption and the acceleration of EHRs and align them with each end-user group. Additionally, both public and private organizations should provide financial and technical supports that will promote the confidence of all stakeholders to subscribe to the system. Finally, it is believed that with time, a clear strategic roadmap that addresses each implementation step and barrier will accelerate the use of EHRs throughout Canada.

\section{References:}

Armstrong, Pat, and Hugh Armstrong. About Canada: Healthcare. Black Point, NS: Fernwood Publishing, 2008. 
Atherley, Gordon. “The Risks of Electronic Health Records.” Fraser Forum (2009): 29-32.

Bishop, Tara F., et al. "Do Provider Attitudes about Electronic Health Records Predict Future Electronic Health Record Use?” Healthcare 3, no. 1 (2015), 5-11. doi:10.1016/j.hjdsi.2014.04.002.

Canadian Medical Association. "How Can Canada Achieve Enhanced Use of Electronic Medical Records?” CMA.ca. 2014. https://www.cma.ca/Assets/assets-library/document/en/advocacy/EnhancedUse-of-EMRs-Discussion-Paper-Final-May-2014.pdf.

Cavoukian, Ann, and Richard C. Alvarez. "Embedding Privacy into the Design of EHRs to Enable Multiple Functionalities: Win/Win.” IPC Ontario, 2012. https://www.ipc.on.ca/images/Resources/2012-03-02-PbD-EHR.pdf

Deutsch, E., George Duftschmid, and W. Dorda. "Critical Areas of National Electronic Health Record Programs: Is Our Focus Correct?” International Journal of Medical Informatics 79, no. 3 (2010): 211-222. doi:10.1016/j.ijmedinf.2009.12.002

Duckett, Stephen. Where to from here: Keeping Medicare Sustainable. Kingston, ON: McGill-Queen's University Press, 2012.

Exeter, Daniel John, Sarah Rodgers, and Clive Eric Sabel. "Whose Data Is It Anyway?: The Implications of Putting Small Area-Level Health and Social Data Online.” Health Policy 114, no. 1(2014): 88-96. doi:10.1016/j.healthpol.2013.07.012

Gagnon, Marie-Pierre, et. al.. “Users' Perspectives of Barriers and Facilitators to Implementing EHR in Canada: A Study Protocol." Implementation Science 41 (2009). doi:10.1186/1748-5908-4-20

Gagnon, Marie-Pierre, et al. (2014). "Electronic Health Record Acceptance by Physicians: Testing an Integrated Theoretical Model." Journal of Biomedical Informatics 48 (2014): 17-27. doi:10.1016/j.jbi.2013.10.010

Ghazisaeidi, Marjan, et al. “A Roadmap to Pre-Implementation of Electronic Health Record: The Key Step to Success.” Acta Informatica Medica 22, no. 2 (2014):133-138. doi:10.5455/aim.2014.22.133-138

Gomillion, David, and Joey George. "Perceived Organizational Readiness Study on EHR Implementation.” AMCIS 2011 Proceedings (2011): 1-24. 
Government of Canada “Jobs and Opportunities: Canada’s Economic Action Plan is Working for Canadians." Government of Canada. n.d.-a. http://actionplan.gc.ca/en/page/jobs-and-opportunities.

Government of Canada. "Canada Health Infoway.” Government of Canada. n.d.-b. http://actionplan.gc.ca/en/initiative/canada-health-infoway

Government of Canada. "History of Health and Social Transfers." Government of Canada. Last modified December 15, 2014. http://www.fin.gc.ca/fedprov/his-eng.asp

Green, Lee A., et al. "Sustaining 'Meaningful Use' of Health Information Technology in Low-Resource Practices.” Annals of Family Medicine 13, no.1 (2015): 17-22. doi:10.1370/afm.1740

Grewal, Gurinder Singh. "Electronic Medical Records in Primary Care: Are We There Yet?” UBC Medical Journal 6, no.1 (2014):15-16.

Health Council of Canada. "Better Health, Better Care, Better Value for All: Refocusing Health Care Reform in Canada." Health Council of Canada. Published September 2013. file://C:/Users/Owner/Documents/HCC_Summative_Report_Accessible_F A.pdf

Health Council of Canada. "The Heath Council of Canada's Departing Message in Support of Future Health Care Reform.” Health Council of Canada. Published March 2014. file:///C:/Users/Owner/Downloads/Letter_to_prime_minister_et_al_2014-0205_Final_ENG.pdf

Kaye, Rachelle, et al. "Barriers and Success Factors in Health Information Technology: A Practitioner's Perspective.” Journal of Management \& Marketing in Healthcare 3, no. 2, (2010):163-175. doi:10.1179/175330310X12736577732764

Kiah, Miss Laiha Mat ., et al. "Open Source EMR Software: Profiling, Insights and Hands-on Analysis." Computer Methods and Programs in Biomedicine 117, no. 2 (2014): 360-382.doi:10.1016/j.cmpb.2014.07.002

KPMG. "Evaluation of the Health Council of Canada (HCC): Final Report." KPMG. $\quad$ Published September 24, file:///C:/Users/Owner/Downloads/HCC_Final_ReportSeptember_24_2013.pdf 
Lau, Francis, Morgan Price, and Jesdeep Bassi. “Toward a Coordinated Electronic Health Record (EHR) Strategy for Canada.” Queen's University. Published 2014. http://moniesonhealth.com/resources/2014-WhitePaperLau.pdf

McGuinn, Carrie Anna, et al. “Users' Perspectives of Key Factors to Implementing Electronic Health Records in Canada: A Delphi Study.” BMC Medical Informatics and Decision Making 12, (2012):1-13. doi: 10.1186/1472-6947-12-105

Morris, Anthony A. "The Electronic Heath Record in Canada: The First Steps.” Health Law Review 14, no. 2 (2005): 14-18.

National Physician Survey. "Backgrounder.” National Physician Survey.ca. Published October 23, 2013.

http://nationalphysiciansurvey.ca/wp-content/uploads/2013/10/OFFICIALRELEASE_NPS-2013-Backgrounder_EN.pdf

National Physician Survey. "Backgrounder.” National Physician Survey.ca. Published December 2, 2014. http://nationalphysiciansurvey.ca/wpcontent/uploads/2014/12/NPS-backgrounder-2014-EN-r.pdf

Nguyen, Lemai, Emilia Bellucci, and Linh Thuy Nguyen. "Electronic Health Records Implementation: An Evaluation of Information System Impact and Contingency Factors.” International Journal of Medical Informatics 83, no. 11 (2014): 779-796. doi:10.1016/j.ijmedinf.2014.06.011

Office of the Auditor General of Canada. "Electronic Records in Canada: An Overview of Federal and Provincial Audit Reports.” Office of the Auditor General of Canada. Published April 2010. http://www.oagbvg.gc.ca/internet/docs/parl_oag_201004_07_e.pdf

Paré, Guy, et al. "Barriers to Organizational Adoption of EMR Systems in Family Physician Practices: A Mixed-Methods Study in Canada." International Journal of Medical Informatics 83, no. 8 (2014): 548-558. doi:10.1016/j.ijmedinf.2014.06.003

Perera, Gihan, et al. Views on Health Information Sharing and Privacy from Primary Care Practices using Electronic Medical Records. International Journal of Medical Informatics 80, no. 2 (2011): 94-101. doi:10.1016/j.ijmedinf.2010.11.00 
PwC. "The Emerging Benefits of Electronic Medical Record Use in Community-Based Care” Pwc.com. Published April 2013. http://www.pwc.com/ca/en/healthcare/publications/pwc-electronic-medicalrecord-use-community-based-care-report-2013-06-en.pdf

Rozenblum, Ronen, et al. "A Qualitative Study of Canada's Experience with the Implementation of Electronic Health Information Technology." Canadian Medical Association Journal, 183, no. 5 (2011): E281-E288. doi:10.1503/cmaj.100856

Scott, Jessica. "Perceived Barriers to the Use of Electronic Health Records for Infectious Disease Surveillance in Canada.” Master's thesis, University of Ottawa, 2015.

Shaw, Norman. "The Role of the Professional Association: A Grounded Theory Study of Electronic Medical Records Usage in Ontario, Canada." International Journal of Information Management 34, no. 2 (2014): 200209.doi:10.1016/j.ijinfomgt.2013.12.007

Urowitz, Sara, et al. "Is Canada Ready for Patient Accessible Electronic Health records? A National Scan.” BMC Medical Informatics \& Decision Making 8, no.1 (2008): 1-7. doi:10.1186/1472-6947-8-33

Webster, Paul Christopher. "The Pocketbook Impact of Electronic Health Records: Part 1.” Canadian Medical Association Journal 182, no. 8 (2010a): 752-753. doi:10.1503/cmaj.109-3225

—."The Pocketbook Impact of Electronic Health Records: Part 2."Canadian Medical Association Journal 182, no. 8 (2010b): 753-754. doi:10.1503/cmaj.109-3226

-. "Experts Call for Health Infoway 'watchdog'." Canadian Medical Association Journal 183, no. 3 (2011): 298-299. doi: 10.1503/cmaj.109-3783

Zelmer, Jennifer, and Simon Hagens. "Advancing Primary Care Use of Electronic Medical Records in Canada." Health Reform Observer Observatoire Des Réformes De Santé 2, no. 3 (2014): 1-10. http://dx.doi.org/10.13162/hro-ors.v2i3.1214 